\title{
Study on the Deformation Law of Super Highway Roadbed Crossed by the Metro Tunnel
}

\author{
Wei BAI ${ }^{1, a}$ \\ ${ }^{1}$ Sinohydro Bureau 7 CO., LTD., Sichuan Chengdu, 610081 \\ a362485229@qq.com
}

\begin{abstract}
Keywords: Crossing Construction, Metro Tunnel, Highway, Surface Subsidence, Monitoring Measurement.
\end{abstract}

\begin{abstract}
According to the Shenzhen Metro Line 7 crossing the Guangzhou Shenzhen highway, the monitoring of highway surface is investigated to determine the deformation control factors and reveal the settlement deformation law of super highway roadbed during the metro tunnel crossing by the mining tunnel method. Then, the existing trend of settlement deformation of highway is improved by adjusting the construction method and supporting measures, which are providing an important reference for the similar engineering.
\end{abstract}

\section{Introduction}

With the development of Chinese subway construction and underground engineering disciplines, the subway construction project has become increasingly complex, and especially the subway tunnels crossing through the existing structures is one of the key factors that restrict the development of subway. Hence, numerous domestic and international builders as well as researchers have taken full advantage of modern technology and methods to explore structural deformation rule of existing structure above the subway tunnels, and the measures to control that deformation for the application to other projects $[1,2]$. Based on a project that shallow tunnels of Beijing-Shanghai high speed rail traveling underneath highway, it revealed the surrounding-rock-deformation mechanism and control laws of support measure deformation. Aim at some tunnel under the highway [3]. Yu studied on the feasibility analysis of double-side pilot tunnel method and corresponding support measures [4]. Sun combining with the project of pipe shed for concealed excavation tunnel under highway in Chengdu, states the pipe shed construction method and technology in high-liquid-limit cohesive-soil stratum [5]. Zhang based on shield tunnel project for a subway tunnel under evaluated line engineering of Beijing-Shanghai high speed railway, discussed the deformation caused by shied tunnel construction under evaluated line engineering [6]. Sirivachirapon combined with the subway project, discuss the impact of subway construction to structure on the surface [7]. The above researches show that aimed at the issues about tunnels crossing under the existing structure, ground-surface settlement is an important factor revealing the influence of that. Therefore, this essay use Shenzhen metro line 7 that under the Guangzhou-Shenzhen highway as an example, based on highway surface monitoring and data analysis, to confirm the control factors of highway subgrade deformation and reveal the subgrade settlement rule of Guangzhou-Shenzhen highway which is influenced by mining method tunnel pass under it. And then by adjusting the construction method and supporting measures to restrain the trend of existing highway roadbed deformation.

\section{Project Profile}

Shenzhen Metro Line 7 covers the downtown major traffic congestion area and secondary transport demand corridor, and link the passenger distribution point outside the Futian-Luohu center. Its completion could organically combine Luohu, Futian and Nanshan to ease traffic pressure in Huaqiang area as well as stimulate the economic and traffic development of developing areas, which meaningfully plays as a bridge between living quarters and working areas in southern half ring of Shenzhen Special Zone. Shenzhen Metro Line 7 stretches from Taian road in the east to the Lishui 
road in the west. The whole length of the line is about $29.798 \mathrm{~km}$. There is a total of 27 stations on the line and 12 stations of these are transfer stations. All stations are underground with an average station spacing about $1.048 \mathrm{~km}$. Line 7 could cross transfer with No. 1, 2, 3, 4, 5 established lines and No.9, 11 lines under construction and No.10, 14, 15 lines in planning. Line 7 travels underneath the No.4 line of Guangzhou-Shenzhen highway, north ring expressway, Pingnan railway and buildings on the ground. Among them, the tunnel between Antuoshan station and Nonglin station has to pass beneath the Guangzhou-Shenzhen highway four times. The crossed area is mainly filled with the undisturbed residual soil, sandy soil, miscellaneous fill, highway filling subgrade and pavement structure. The upside of the tunnel is residual soil (part is back fill), bottom is rock with rich water, which both severely influence the safety of crossing engineering construction and highway functioning.

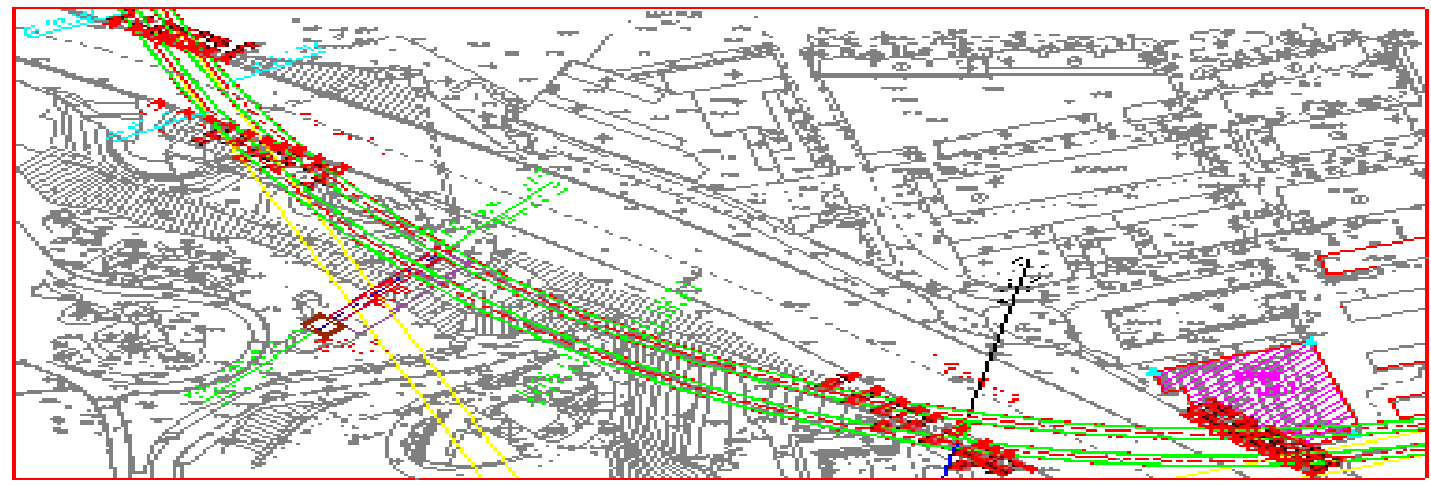

Fig. 1 Crossing GuangShen Super Highway

In order to collect, feedback and analysis the information about deformation which are caused in the construction of tunnel crossing super highway, and ensure safety of the construction of under-passing the existing highway and the operation of Guangzhou Shenzhen highway. To this end, the authors arrange monitoring points which reveal ground settlement along the road shoulder, as shown in figure 1 , surface subsidence controlling value is $30 \mathrm{~mm}$.

\section{Results Analysis}

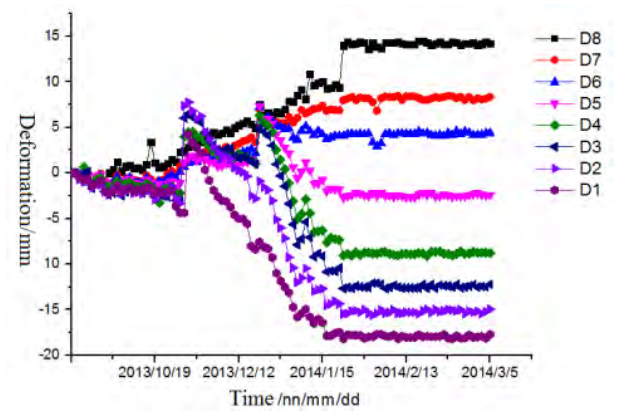

(a) The north side of high speed road

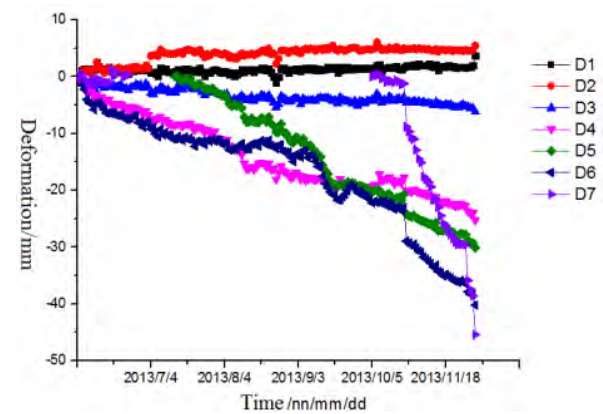

(b) The south side of high speed road

Fig. 2 Relationship between Surface Subsidence with Time in Small Mileage during Crossing Guangshen Highway

Figure 2 shows the curve changing with time of the ground subsidence deformation when the Guangzhou Shenzheng Super Highway crossed by the metro tunnel. The monitoring time is from September 1, 2013 to the time when the Deformation becomes stabile. It can be founded from figure 2(a) that: (1) Trends of each monitoring data are gradually increased or decreased, and become stable with the lapse of time. And the subsidence curve tends to level. (2) The curves of D1 D5 monitoring point shows that the subsidence are increasing with the growth of time -subsidence, eventually become constant, and D1 D5 monitoring points located on the left side of the north road shoulder. (3) While D6 D8 monitoring subsidence curves for subsidence shows the sedimentation is decreased 
with time past - uplifting and eventually being stabilized. It can be founded from figure 2(b) that: (1) Trends of each monitoring data are gradually incremented or decremented, and become stable with the lapse of time, and the subsidence curve tends to level. (2) The curves of D1 D2 monitoring point shows that the subsidence are basically unchanged with the growth of time, and D1 $\sim$ D2 monitoring points located on the right side of the south road shoulder.

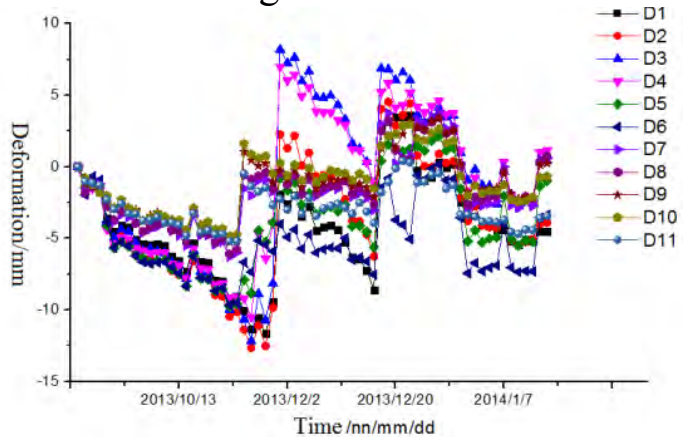

(a) The north side of high speed road

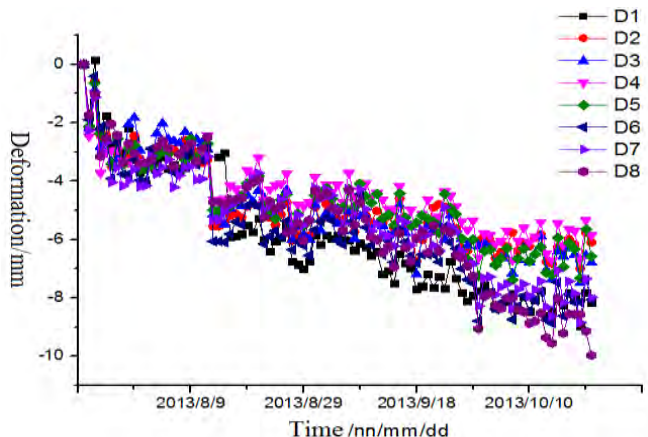

(b) The south side of high speed road

Fig. 3 Relationship between Surface Subsidences with Time in High Mileage during Crossing Guangshen Highway

Figure 3 shows the curve changing with time of the ground subsidence when the Guangzhou Shenzheng Super Highway crossed by the metro tunnel. The monitoring time is from September 1, 2013 to the time when the Deformation becomes stabile. It can be founded from figure 3(a) that: (1) D1 D1 1 settlement deformation curve of the monitoring points increases at first and then decreases, then increases and then decreases after, which means settle at first and then uplift, and then settle again and then uplift, constantly changing, and becoming stable finally. (2)Among D1 D11, the maximum quantity of uplift appears at D3 points, its uplift quantity is $6.89 \mathrm{~mm}$. The maximum quantity of subsidence appears at D2 points, its subsidence quantity is $12.52 \mathrm{~mm}$. It can be founded from figure 3(b) that: (1)D1 D8 settlement deformation curves are increasing with the growth of time , and being Stabile finally.(2) Among D1 D11, the maximum quantity of settlement appears at D8 points, its settlement quantity is $9.97 \mathrm{~mm}$.

\section{Conclusion}

According to the Shenzhen Metro Line 7 passing underneath the Guangzhou Shenzhen highway, the monitoring of highway surface is investigated to determine the deformation control factors and reveal the settlement deformation law of super highway roadbed during the metro tunnel crossing by the mining tunnel method. And the conclusions are as follow:

1. The uneven settlement deformation of roadbed is caused when super highway crossed by the new-built metro tunnel, thus causing the uneven deformation of road surface. Generally, there is always an obvious groove.

2. The longitudinal settlement deformation law of super highway roadbed caused by metro tunnel crossing can be divided into four steps: slight deformation stage, surge deformation stage, low speed deformation stage and stabilization stage.

3. The settlement deformation characteristic of super highway roadbed during the metro tunnel crossing is that the trends of each monitoring data are gradually increased or decreased, and become stable with the lapse of time, that is to say the subsidence curve tends to level.

\section{References}

[1]Wang Wei. Research on Ground Settlement Controls of Shallow and Large Section Loess Tunnel through High Speed Highway[D]. Beijing Jiaotong University Master Degree Thesis, 2007.

[2]Dong Min. Research on surrounding rock stability of large section tunnel construction under the existing highway[D]. Central South University Master Degree Thesis, 2010. 
[3]Wang Shu. Security Risk Management of Large-Span Shallow Tunnel Beneath Highway in Beijing to Shanghai High-Speed Railway[D]. Beijing Jiaotong University Master Degree Thesis, 2007.

[4]YU Xiao-lin, LUO Xia. 2010. Numerical Analysis of the Feasibility of Metro Tunnel Crossing Super Highway[J]. Highways \& Automotive Applications(05): 182-185.

[5]SUN Shuang-yin, SUN Rong-bo. 2009. construction of the long and large pipe shed and its applicationg in metro tunnel crossing super highway roadbed[J]. Sichuan Architectural(S1): 251-252.

[6]Zhang li-yang, Analysis on Deformation Induced by Shield Tunnel of Subway Crossing Elevated Lines of High-speed Rail and the Study on Risk Control[D], Beijing Jiaotong University Master Degree Thesis, 2012.

[7]A. Sirivachirapon, N. Phienwej. Ground movements in EPB shield tunneling of Bangkok subway project and impacts on adjacent buildings[J]. Tunnelling and Underground Space Technology, 2012, 30:10-24. 